Revue Revue de l'histoire des religions

de Ihistoire des religions pendant et frère jumeau d'Israël. Histoire et enjeux

\title{
Les images bibliques de Rome dans les textes juifs et chrétiens. Les Kittim, Babylone, Tyr et Ésaü- Édom
}

Biblical Images of Rome in Jewish and Christian Texts: Kittim, Babylon, Tyre, and Esau - Edom

Hervé Inglebert

\section{(2) OpenEdition}

Journals

Édition électronique

URL : http://journals.openedition.org/rhr/8555

DOI : 10.4000/rhr.8555

ISSN : 2105-2573

Éditeur

Armand Colin

Édition imprimée

Date de publication : 1 juin 2016

Pagination : 223-254

ISBN : 978-2-200-93060-8

ISSN : 0035-1423

Référence électronique

Hervé Inglebert, « Les images bibliques de Rome dans les textes juifs et chrétiens. Les Kittim, Babylone, Tyr et Ésaü-Édom », Revue de l'histoire des religions [En ligne], 2 | 2016, mis en ligne le 01 juin 2019, consulté le 05 septembre 2020. URL : http://journals.openedition.org/rhr/8555 ; DOI : https:// doi.org/10.4000/rhr.8555 


\section{Les images bibliques de Rome dans les textes juifs et chrétiens Les Kittim, Babylone, Tyr et Ésaü-Édom}

Du II siècle avant notre ère au IV siècle de notre ère, les Juifs ont décrit et compris Rome à travers les images bibliques des Kittim, de Babylone, de Tyr et d'Ésaü - Édom. Ce dernier thème devint prépondérant chez les Juifs rabbiniques, alors que les chrétiens des $I^{e r}-v^{e}$ siècles privilégièrent le parallèle avec Babylone. Cependant, le thème d'Ésaü - Édom est attesté chez deux auteurs chrétiens en contact avec des Juifs rabbiniques. On trouve les Romains comme fils d'Ésaü en 337 chez Aphraate, qui vivait en Mésopotamie sassanide. Et Jérôme, installé à Bethléem à la fin du IVe siècle, signale, pour la rejeter, la théorie juive de l'identification des Romains à Édom dans ses commentaires exégétiques. Les sources chrétiennes peuvent ainsi aider à préciser les datations des textes rabbiniques.

\section{Biblical Images of Rome in Jewish and Christian Texts: Kittim, Babylon, Tyre, and Esau - Edom}

Between the $2^{\text {nd }}$ century $B C E$ and the $4^{\text {th }}$ century $C E$, Jews have described and understood Rome through the following biblical categories: the Kittim, Babylon, Tyre and Esau - Edom. The theme of Esau - Edom became predominant in rabbinic literature, whereas from the $1^{\text {st }}$ to the $5^{\text {th }}$ century, Christians tended to favour the parallel with Babylon. However, the theme of Esau - Edom does appear in the works of two Christian authors who were in touch with rabbinic Jews. The Romans are described as sons of Esau by Aphrahat, who lived in Sassanian Mesopotamia, as early as 337. Later on, Jerome, who lived in Bethleem at the end of the $4^{\text {th }}$ century, mentions (and rejects) the Jewish identification of the Romans with Edom in some of his exegetical commentaries. Christian sources may therefore help to date the rabbinic tradition concerning the identification of Rome with Esau - Edom more precisely. 
Les Juifs ont commencé à être en contact avec Rome à partir des années de la révolte maccabéenne. Si Rome apparut comme une puissance protectrice après l'alliance de $161 \mathrm{av}$. J.-C., et ce durant un siècle ${ }^{1}$, les sentiments envers elle changèrent en 63 av. J.-C., lors de la prise de Jérusalem par Pompée et sa visite du temple, qui fut ressentie comme une profanation. Cette conception négative s'accrut au fil des révoltes contre Rome (66-74 en Palestine, 115-117 en Égypte, Cyrénaïque et à Chypre, 132-135 en Palestine) et des répressions qui s'ensuivirent ${ }^{2}$. Pour comprendre la signification de l'existence et des actions de Rome, les lettrés juifs utilisèrent divers thèmes bibliques. Les chrétiens héritèrent ensuite de certaines de ces interprétations. On étudiera quatre identifications bibliques de Rome, en insistant sur le cas d'Édom, et en privilégiant les textes chrétiens latins, à cause du statut particulier d'exégète de Jérôme.

\section{ROME ET LeS KitTIM}

La première identification entre Rome et les données bibliques a été faite en posant une équivalence entre Rome et les Kittim. Ceux-ci étaient sans doute à l'origine les habitants de Kittion (à Chypre) et furent présentés comme un peuple maritime dans la Bible. Ensuite, les Kittim étant des fils de Yavan (Genèse 10, 4), ils furent identifiés aux Grecs et plus précisément aux Macédoniens (1 Maccabées 1, 1 et 8,5 ; Jubilés XXIV, 28). Enfin, à partir de la révolte maccabéenne, les Kittim furent identifiés aux Romains, car l'aspect extérieur et maritime leur convenait alors mieux qu'aux Grecs de Syrie. Daniel 11, 30 utilise ainsi le terme Kittim pour désigner les Romains qui obligèrent Antiochos IV à abandonner la conquête de l'Égypte qu'il avait entreprise en 168 av. J.-C. Cette équivalence est également présente dans certains passages de la Septante qui traduisent les Kittim

1. Ceci explique la présentation positive qui est faite de Rome dans les Livres des Maccabées.

2. Pour le contexte général, voir Maurice Sartre, D’Alexandre à Zénobie. Histoire du Levant antique (IVe siècle av. J.-C. - III siècle apr. J.-C.), Paris, Fayard, 2001 ; Fergus Millar, The Roman Near East, 31 B.C.-A.D. 337, Cambridge (Mass.), Harvard University Press, 1993. 
ou le pays des Kittim par l'Italie ou les Romains (Nombres 24, 24 ; Ezéchiel 27, 6 ; Daniel 11,30) ${ }^{3}$, ainsi que dans les targums araméens. On débat depuis longtemps sur l'identité des Kittim présents dans certains écrits de Qumrân, en particulier le Rouleau de la guerre, le pesher de Habaquq et celui sur Nahum. Selon les textes, on pense pouvoir associer les Kittim avec les Grecs ou les Romains ${ }^{4}$. Dans ce dernier cas, comme les Kittim sont présentés de manière négative, on pense à une rédaction après la prise de Jérusalem par Pompée.

Tout ceci est bien connu. En revanche, on a moins fait attention à la distinction entre les lecteurs des textes hébreux et ceux des traductions en grec, araméen ou latin. Si les premiers pouvaient poser l'équivalence entre Kittim et Romains dans leurs commentaires, les autres, qui lisaient selon les passages, soit « Kittim», soit « Romains/Italiens », ne pouvaient plus établir un lien entre les deux noms, car les Kittim étaient désormais soit pensés comme un peuple d'autrefois, soit comme désignant les Macédoniens. C'est pourquoi l'équivalence entre Kittim et Romains ne perdura guère après 70 dans les textes chrétiens, comme le montre le texte de la Vulgate. La forme latine des Kittim fut le terme Cetthim, utilisé six fois par Jérôme dans sa traduction de la Bible, pour désigner l'un des fils de Yavan $^{5}$ ou un peuple maritime ${ }^{6}$ ayant agi contre $\mathrm{Tyr}^{7}$, et identifiable avec les Macédoniens ${ }^{8}$ (puisqu'Alexandre avait détruit Tyr). Mais tout en suivant l'hébreu, Jérôme reprit également

3. Si au $\mathrm{II}^{\mathrm{e}}$ siècle av. J.-C., la distinction juridique était très nette entre Romains et alliés italiens à cause du statut de citoyen romain, la présence des alliés dans les armées romaines (en particulier, ils fournissaient l'essentiel des flottes sous commandement romain), et leur participation au commerce maritime en Méditerranée orientale expliquent que les hellénophones ne distinguaient pas toujours entre Romains et Italiens, comme cela est attesté à Délos.

4. André Dupont-Sommer, Les Écrits esséniens découverts près de la mer Morte, [1959], Paris, Payot, 2e édition, 1968, p. 352. Mireille Hadas-Lebel, Jérusalem contre Rome, Paris, Le Cerf, 1990, p. 34-36.

5. Genèse 10, 4 : « filii autem Iavan Elisa et Tharsis Cetthim et Dodanim »; 1 Chroniques 1, 7 : « filii autem Iavan Elisa et Tharsis Cetthim et Dodanim ».

6. Jérémie 2, $10:$ «transite ad insulas Cetthim et videte et in Cedar mittite et considerate vehementer et videte si factum est huiuscemodi ».

7. Isaïe $23,1:$ « onus Tyri ululate naves maris quia vastata est domus unde venire consueverant de terra Cetthim revelatum est eis »; Isaie 23, 12 : « et dixit non adicies ultra ut glorieris calumniam sustinens virgo filia Sidonis in Cetthim consurgens transfreta ibi quoque non erit requies tibi ».

8. 1 Maccabées 1, 1: « et factum est postquam percussit Alexander Philippi Macedo qui primus regnavit in Graecia egressus de terra Cetthim Darium regem Persarum et Medorum ». 
les interprétations déjà présentes dans la Septante, qui remplaçait parfois les Kittim hébraïques par l'Italie ou Rome ${ }^{9}$. Lisant la Bible en traduction grecque ou latine, et identifiant les Kittim/Cetthim aux Macédoniens grâce à 1 Maccabées 1,1 , les commentateurs chrétiens n'ont pas associé les Kittim/Cetthim avec Rome.

\section{RoMe et BABYLONE}

\section{Dans les textes juifs}

La deuxième identification pour comprendre Rome à travers la Bible fut de la poser comme équivalente à Babylone, ce qui fut fait après 70. Les sources juives traitèrent la question de quatre manières, que l'on peut rassembler en deux groupes distincts par la datation et par la méthode, implicite ou explicite.

Dans certains textes de la fin du $\mathrm{I}^{\text {er }}$ siècle et du début du II $^{\mathrm{e}}$ siècle de notre ère, l'identification est cryptée. Des apocalypses rédigées vers 100, comme II Baruch et IV Esdras, décrivent la prise de Jérusalem et la destruction du premier Temple par Nabuchodonosor. Derrière Babylone, il faut entendre Rome. L'histoire s'est répétée puisque Jérusalem fut prise deux fois. Mais elle se répétera jusqu'au bout, et, comme Babylone fut châtiée, Rome le sera à son tour. La seule différence sera que le messie de Yahvé ne sera plus un roi étranger comme Cyrus, mais celui qui instaurera le règne d'Israël. La finalité commune de ces textes est de montrer que l'avenir jadis révélé a été réalisé, ce qui fonde un nouvel espoir pour un futur eschatologique d'Israël.

Une deuxième manière, contemporaine de la première, est plus explicite. Elle identifie Rome à Babylone, ou parle de celle-ci dans un contexte où elle désigne Rome de façon évidente. C'est le cas dans le livre V des Oracles sibyllins, qui rapproche les deux noms (v. 139 et 143) et qui fait allusion aux cataclysmes cosmiques qui consumeront « la grande mer et Babylone elle-même et la terre d'Italie»

9. Nombres 24, 24: «venient in trieribus de Italia superabunt Assyrios vastabuntque Hebraeos et ad extremum etiam ipsi peribunt»; Ezéchiel 27, 6 : «quercus de Basan dolaverunt in remos tuos transtra tua fecerunt tibi ex ebore indico et praetoriola de insulis Italiae »; Daniel 11,30: «Et veniet super eum trieres, et Romani: et percutietur, et revertetur, et indignabitur contra testamentum sanctuarii, et faciet: reverteturque et cogitabit adversum eos, qui dereliquerunt testamentum sanctuarii ». 
(v. 159-160). On retrouve les mêmes thèmes dans la Première Épître de Pierre adressée à l'Église de Rome que le texte appelle « l'élue de Babylone », et dans l'Apocalypse de Jean, avec la grande prostituée de Babylone assise sur ses sept collines (17, 1-6 et 18).

On retrouve ensuite des identifications explicites entre Babylone et Rome dans des textes midrashiques, en lien avec l'équivalence entre Rome et la «fille de Babylone», une formule présente dans certains textes bibliques, où elle désignait Babylone elle-même, mais qui fut ensuite comprise comme désignant Rome ${ }^{10}$.

Enfin, une autre identification entre Rome et Babylone est présente dans le récit des origines de Rome associé à Abba Qolon (Cantique Rabbah 1.6), puisque ce dernier mélange l'eau de l'Euphrate à de l'argile afin de fonder Rome - Babylone. L'utilisation massive de la brique pouvait faire penser à la tour de Babel, mais aussi à l'architecture romaine des thermes et des murailles ${ }^{11}$.

Toutefois, l'utilisation de Babylone comme surnom de Rome avait ses limites. Si les deux capitales se confondaient comme ennemies du Temple, le schéma de la succession des empires de Daniel 2, 36-45 ne permettait pas de confondre le premier et le quatrième empire. L'identification ne pouvait donc être que typologique. De plus, après 224-226 de notre ère, la coexistence de l'empire romain et de l'empire perse sassanide, qui contrôlait la Babylonie, rendait l'équivalence entre Rome et Babylone moins pertinente. En effet, le souvenir de Cyrus amenait les Juifs à considérer positivement les Sassanides dont la capitale Ctésiphon était proche de l'ancienne Babylone. Et le fait que la Babylonie devint à partir du $\mathrm{III}^{\mathrm{e}}$ siècle une terre de mission rabbinique a pu valoriser cette région. Ceci pourrait expliquer le moindre intérêt ultérieur de l'identification de Rome à Babylone dans le judaïsme.

\section{Dans les textes chrétiens latins}

L'équivalence entre Rome et Babylone connut en revanche une grande fortune chez les chrétiens, pour deux raisons. La première est que l'équivalence était posée dans le Nouveau Testament et en

10. M. Hadas-Lebel, Jérusalem contre Rome, p. 435. Mais le Midrash sur les Psaumes est tardif, et même médiéval dans sa rédaction finale.

11. M. Hadas-Lebel, Jérusalem contre Rome, p. 359, 361 et 434. Cantique Rabbah est daté du milieu du $\mathrm{VI}^{\mathrm{e}}$ siècle, mais contient des traditions plus anciennes. 
particulier dans l'Apocalypse de Jean ${ }^{12}$. Et même si la réception de ce texte fut très discutée jusqu'au $\mathrm{IV}^{\mathrm{e}}$ siècle et qu'il fut en réalité peu commenté, la situation juridique précaire des chrétiens jusqu'à Constantin, et ensuite celle des chrétiens jugés schismatiques ou hérétiques par le pouvoir impérial, justifia d'assimiler durant des siècles le pouvoir romain jugé persécuteur à Babylone. La seconde est que les chrétiens étaient détachés des souvenirs historiques juifs : pour eux, Babylone et Rome, en détruisant Jérusalem, n'avaient fait que châtier un peuple deux fois rebelle envers Dieu pour avoir persécuté les prophètes et le Christ ${ }^{13}$. Aussi, la comparaison entre Babylone et Rome n'était-elle pas nécessairement négative. Pour toutes ces raisons, Babylone eut un rôle symbolique et rhétorique important chez les chrétiens. Dans la seule production latine, on trouve une soixantaine d'équivalences entre Babylone et Rome, de Tertullien à Bède le Vénérable. Mais les auteurs du $\mathrm{III}^{\mathrm{e}}$ siècle et du début du $\mathrm{IV}^{\mathrm{e}}$ siècle ne font que commenter des passages bibliques, comme l'Apocalypse ${ }^{14}$ ou la Première Épître de Pierre ${ }^{15}$.

Si l'on excepte une remarque de Paulin de Nole sur la piété des deux villes de son temps, Jérusalem et Rome « fille de Babylone », comparaison qui n'est pas défavorable à l' $U r b s^{16}$, le parallèle entre

12. Sur ce point, voir l'interprétation de Robert Beauvery, «L'Apocalypse au risque de la numismatique. Babylone, la grande prostituée et le sixième roi. Vespasien et la déesse Rome », Revue biblique 90, 1983, p. 243-260.

13. Jérôme, Commentarii in Isaiam 11.40.1: «iuxta historiam recepit Hierusalem de manu domini duplicia peccata sua; semel a Babyloniis, secundo a Romanis »; In Ezechielem 2.7 : « hoc in illo populo factum sit non solum sub Babyloniis, sed et sub Romanis quando peruenit in eos usque in finem ira Dei »; ibid. 4.16: "Hierusalem: uel haec quae a Babylonio et Romano igne succensa est »; ibid. 11.36 : « quamobrem dispersit eos, uel sub Babylonia captiuitate, uel sub Romana ».

14. Tertullien, Aduersus Marcionem III.13.10: «Sic et Babylon etiam apud Iohannem nostrum Romanae urbis figura est, proinde magnae et regno superbae et sanctorum dei debellatricis » (= Aduersus Iudaeos 9); Victorin de Petau, Commentarii in Apocalypsim Iohannis 8.2 : « Sunt igitur scripta quae sunt in tubis et in fialis aut plagarum orbi missarum clades aut ipsius Antichristi insania aut populorum detrectatio aut plagarum differentia aut spes in regno sanctorum aut ruina ciuitatum aut ruina Babylonis, id est ciuitatis Romanae ».

15. Eusèbe de Césarée, Histoire ecclésiastique 2.12.2 dans la traduction de Rufin : «Petrus in prima epistula sua, quam de urbe Roma scribit, meminerit Marci, in qua tropice Romam Babylonam nominarit, cum dicit: "salutat vos ea, quae in Babylone electa est et Marcus filius meus" ».

16. Lettre 29.13 : « hanc ergo filia Sion hactenus habuit et desiderat, nunc filia Babylonis habet et admiratur, quia iam et ipsa urbs in pluribus filia Sion est quam filia Babylonis; et ideo miratur in humilitatis obscuro et ueritatis luce uiuentem 
les deux villes fut principalement développé entre 380 et 420 par trois auteurs, Jérôme, Augustin et Orose, dans des perspectives très différentes. Jérôme fit des comparaisons en contexte exégétique et il développa principalement deux problématiques. La première portait sur la question de savoir si les prophéties sur Jérusalem ou les Juifs signalées dans l'Ecclésiaste ${ }^{17}$, Isaï ${ }^{18}$, Jérémie ${ }^{19}$, Ezéchiel ${ }^{20}$, Michée ${ }^{21}$ et Sophonie ${ }^{22}$ s' accomplirent historiquement au temps de Babylone ou de Rome, ou des deux, les arguments en faveur de cette dernière étant à la fois théologiques (fondés sur l'expansion de l'Église) et historiques (établis sur le fait que la captivité de Rome était plus durable et absolue que celle de Babylone). Il ne s'agissait pas là d'identifier les deux villes, sinon dans leur fonction d'instrument du châtiment divin, mais au contraire de tenter de distinguer ce

et fidei incitamenta diuitibus, angustiarum solatia pauperibus ministrantem, quamquam illa quietis et latebrae suae apud Hierusalem in Romanis modo turbis aestuans clamet: heu me! quod incolatus meus prolongatus est ».

17. In Ecclesiasten 12.1 : « et tam cogitationes malas, quam libidines fugiat, sciens stultitiam adolescentiae copulatam recordetur que semper creatoris sui, antequam dies Babyloniae ac Romanae captiuitatis adueniant ».

18. In Isaiam 1.1.9: «ex quo ostenditur superiora quae contra Hierusalem et Iudam sermo propheticus comminatus est, non ad Babylonicae captiuitatis referenda tempus, sed ad ultimam Romanorum»; 1.2.5: «alii autem putant hoc non pertinere ad Romana tempora, sed ad superiora, priusquam a Babyloniis uastarentur »; 1.2.10: «ideo praenuntio uobis quae uentura sint mala et hortor ut ingrediamini petras et abscondamini in speluncis a facie Babylonii uel Romani exercitus, quando omnia uastabuntur»;1.2.11 : «cum hostes uenerint et omnem prouinciam Babylonius aut Romanus mucro uastauerit, et circumsederint agmina bellatorum Hierusalem »; 2.3.1 : «quod sequitur, de captiuitate uentura, quam alii ad Babylonios, alii referunt ad Romanos»; 9.28.9: «sed conterantur et illaqueentur, et uel a Babylonio, uel a Romano capiantur exercitu»; 14.52.11 : « alii quae de Babylone diximus, de Romano regno interpretantur, quod in aduentu Christi qui eos liberaturus sit, haec omnia compleantur ».

19. In Hieremiam 3, p. 206 : « relinqueris, ait, sola ab hereditate tua, quam dedi tibi, et seruire te faciam inimicis tuis in terra, quam ignoras, uel sub Babyloniis uel, ut est uerius, sub Romanis »; 4, p. 235 : «perspicue non de Babylonia, sed de Romana dicitur captiuitate ».

20. In Ezechielem 2.5: «possumus patres qui comederint filios et filios qui comederint patres, non solum in Babylonia sed et in Romana obsidione intellegere; illud quod dicitur: et uentilabo uniuersas reliquias tuas in omnem uentum, magis ad Romanam pertinet captiuitatem quando in toto orbe dispersi sunt ».

21. In Michaeam 1.2: « et primam ab Assyriis, Babyloniisque captiuitatem, et secundam a Romanis»; 1.2: «captiuitate uidelicet, uel Babylonica, uel Romana ».

22. In Sophoniam 1: «in tempore et in die captiuitatis Hierusalem uel a Babyloniis uel a Romanis »; 1: « uel de Babylonica captiuitate accipe, uel de extrema quam passi sunt a Romanis ». 
qui revenait à chacune. La seconde approche visait en revanche à comprendre typologiquement Rome derrière Babylone, comme dans le Nouveau Testament, et se trouve dans le commentaire sur Isaï $^{23}$. Ces considérations sur la lecture historique des prophéties étaient extrêmement importantes, car elles renvoyaient à des débats cruciaux. En effet, le destin catastrophique du peuple juif en Judée, et en particulier, la prise et la destruction de la ville et du temple en 70, était considéré, au moins depuis Justin, comme un argument essentiel de la véracité du discours messianique chrétien.

Augustin développa ses idées dans un contexte théologique et non exégétique. Il insista d'abord, en 404, à l'occasion d'un aduentus d'Honorius à Rome, sur le fait que Babylone désignait le pouvoir terrestre, ce qui pouvait s'appliquer à Rome ${ }^{24}$. Cette lecture allégorique se fondait sur une réalité historique, dans laquelle Babylone et Rome étaient équivalentes pour deux raisons. D'abord, elles avaient été hégémoniques (l'empire de Babylone étant pour Augustin une synthèse entre l'empire assyrien de la tradition classique et l'empire babylonien de la Bible), même si le centre de leur pouvoir était pour l'une en Orient et pour l'autre en Occident ${ }^{25}$. Ensuite, elles s'étaient succédé dans le temps, assurant ainsi la continuité temporelle de la cité terrestre ${ }^{26}$. Ainsi, Rome apparaissait

23. In Isaiam 6.14.2: " quod si sequentes litteram, spe se falsa decipiunt, quis eis concedet, ut Roma uocetur Babylon, et Nabuchodonosor rex Romani imperii? »; 13.47.1 : « licet ex eo quod iuxta LXX scriptum est: filia Babylonis, non ipsam Babylonem quidam, sed Romanam urbem interpretentur, quae et in apocalypsi Ioannis et in epistola Petri, Babylon specialiter appellatur »; 14.52.11 : «alii quae de Babylone diximus, de Romano regno interpretantur, quod in aduentu Christi qui eos liberaturus sit, haec omnia compleantur ».

24. Enarratio in Psalmos, Psalmus 86.8 : « uenerunt de Babylone principes, credentes de saeculo principes uenerunt ad urbem Romam, quasi caput Babylonis ».

25. De ciuitate Dei XVIII.22 : « condita est ciuitas Roma uelut altera Babylon et uelut prioris filia Babylonis, per quam deo placuit orbem debellare terrarum et in unam societatem rei publicae legum que perductum longe late que pacare ».

26. De ciuitate Dei XVIII.27 : «tenduntur autem hi dies a rege Latinorum Proca siue superiore Auentino usque ad Regem Romulum iam Romanum, uel etiam usque ad regni primordia successoris eius Numae Pompilii (Ezechias quippe rex Iuda eo usque regnauit); ac per hoc per ea tempora isti uelut fontes prophetiae pariter eruperunt, quando regnum defecit Assyrium coepit que Romanum; ut scilicet, quem ad modum regni Assyriorum primo tempore extitit Abraham, cui promissiones apertissimae fierent in eius semine benedictionis omnium gentium, ita occidentalis Babylonis exordio, qua fuerat Christus imperante uenturus, in quo implerentur illa promissa, ora prophetarum non solum loquentium, uerum etiam scribentium in tantae rei futurae testimonium soluerentur ». 
comme une Babylone d'Occident ${ }^{27}$. En conclusion, chez Augustin, dans le De ciuitate Dei XVI-XVIII, rédigé vers 420, le rapport entre les deux villes n'était pas typologique du point de vue scripturaire, mais du point de vue historique, les deux villes étant des figures successives et équivalentes du saeculum $^{28}$.

Chez Orose, vers 417, les parallèles entre Rome et Babylone furent bien plus systématiques que chez Augustin, car selon lui, les deux villes avaient non seulement connu des destins successifs ${ }^{29}$, mais surtout des histoires chronologiquement comparables. En effet, Orose supposait que les quatre empires de Daniel étaient ceux de Babylone, des Macédoniens, de Carthage et de Rome, en les reliant aux quatre points cardinaux (est, nord et sud, ouest). Mais alors que les empires des Macédoniens et de Carthage étaient contemporains et duraient sept siècles ${ }^{30}$, celui de Babylone était antérieur et celui de Rome postérieur. De plus, ces deux empires duraient quatorze siècles ${ }^{31}$, tout en coïncidant durant un peu plus de deux siècles, de la fondation de Rome à la prise de Babylone par Cyrus, ce qui permettait de passer le relais de l'une à l'autre (en ignorant l'empire perse achéménide). Le plus important pour Orose était le parallèle chronologique qu'il pensait pouvoir établir entre les deux destins de Babylone et de Rome. En particulier, les deux villes avaient été prises lors de leur $1164^{\mathrm{e}}$ année (ce qui lui permettait d'expliquer le sac de Rome en 410), mais le devenir de la Rome chrétienne serait ensuite différent de celui de la Babylone païenne ${ }^{32}$. Augustin se distingua ensuite de cette interprétation

27. De ciuitate Dei XVI.17: «quando natus est Abraham, qui erat annus circiter millensimus ducentensimus ante conditam Romam, ueluti alteram in occidente Babyloniam»; XVIII.2 : «Babylonia, quasi prima Roma [...] ubi et ipsa Roma quasi secunda Babylonia est ».

28. Robert Markus, Saeculum. History and Society in the Theology of St. Augustine, Cambridge, Cambridge University Press, 1970.

29. Historiarum aduersum paganos libri 2.3.5: «[...] unum Deum disposuisse tempora et in principio Babyloniis et in fine Romanis ».

30. Ibid. VII.2.9 : « Regnum Cartaginiense a conditione usque ad euersionem eius, paulo amplius quam septingentis annis stetit, aeque regnum Macedonicum a Carano usque ad Persem paulo minus quam settingentis ».

31. Ibid. VII.2.12. : "Poteram quoque ostendere eundem duplicatum numerum mansisse Babyloniae quae post mille quadragentos et quod excurrit annos ultime a Cyro rege capta est, nisi praesentium contemplatione reuocarer ».

32. Ibid. II.3.2-6: «2.Ita Babylon, post annos MCLX et propemodum quattuor quam condida erat, a Medis et Arbato, rege eorum, praefecto autem suo, spoliata opibus et regno atque ipso rege priuata est ; ipsa tamen posteo aliquamdiu mansit incolumis. 
chronologique d'Orose ${ }^{33}$, qui permettait de fonder un système de datation de la fin du monde (car Rome, fondée en 753 pour Orose qui suivait Tite-Live, devait donc perdurer comme dernier empire de Daniel jusqu'en 646 apr. J.-C.), alors que l'évêque d'Hippone refusait absolument toute spéculation eschatologique.

En conclusion de ces comparaisons entre Babylone et Rome, il faut insister sur la diversité des approches, liée à celle des genres littéraires. En particulier, dans leur réflexion historique ou théologico-historique, Orose et Augustin ne s'intéressent pas au destin du peuple juif. Ce dernier est absent des Histoires d'Orose, où le parallèle entre Babylone et Rome ne concerne que le pouvoir universel. Chez Augustin, la distinction Babylone-Jérusalem existe, mais elle est strictement théologique et allégorique, car renvoyant à celle entre la cité terrestre et la cité céleste. Dans les deux cas, l'histoire juive est absente ou marginale, et la Jérusalem terrestre n'a guère d'intérêt. En revanche, Jérôme a bien abordé le problème dans ses commentaires exégétiques. Mais son approche est essentiellement historique, afin de déterminer la valeur passée (babylonienne) ou actuelle (romaine) des prophéties portant sur la punition d'Israël. On remarque qu'après Augustin, le thème fut délaissé. Pour l'exégèse, on se contenta de lire Jérôme. Le lien historique entre Rome et Babylone, trop lié au contexte du sac de 410 (pour Orose) ou qui supposait une trop forte distinction entre le salut chrétien et la politique terrestre (chez Augustin) ne fut pas repris. Après 600, Isidore de Séville réutilisa le thème, en insistant sur l'unité du processus de la captivité des Juifs, dans un contexte qui était désormais celui d'une société devenue chrétientée ${ }^{34}$.

3.Similiter et Roma post annos totidem, hoc est MCLX et fere quattuor, a Gothis et Alarico rege eorum, comite autem suo, inrupta et opibus spoliata non regno, manet adhuc et regnat incolumis, 4.quamvis in tantum arcanis statutis inter utramque urbem conuenientiae totius ordo seruatus sit ut et ibi praefestus eius Arbatus regnum inuaserit, et hic praefectus eius Attalus regnare temptarit, tametsi apud hanc solam merito Christiani imperatoris adtemptatio prafana uacuata sit. [...] 6.Ecce similis Babyloniae ortus et Romae, similis potentia, similis magnitudo, similia tempora, similia bona, similia mala, tamen non similis exitus similisue defectus. Illa enim regnum amisit, haec retinet ; illa interfectione regis orbata, haec incolumi imperatore, secura est. »

33. Hervé Inglebert, Les Romains chrétiens face à l'histoire de Rome, Paris, Institut d'Études Augustiniennes, 1996, p. 485-494.

34. De fide catholica contre Iudaeos II.11.2 : «Quae captivitas, et licet sub Babylonis tempore ex parte completa sit, plenius tamen sub Romana captivitate impleta est, quando universam Judaeam Romanus vastavit exercitus, atque urbs Jerusalem eversa atque succensa est ». 


\section{RoMe ET TYR}

Une troisième identification juive fut celle de Rome à Tyr, autre ennemi de Jérusalem pour deux raisons. La première est l'oracle d'Ezéchiel 28 contre le prince de Tyr, qui fut parfois appliqué à Rome. La seconde est que le nom de Tyr étant posé comme ennemi, il pouvait être ensuite appliqué à Rome ${ }^{35}$. Mais cette équivalence, restée marginale dans les sources rabbiniques, ne semble pas avoir été reprise par les chrétiens latins, et on ne fait donc que la mentionner.

\section{ROME ET ÉSAÜ/ÉdoM}

\section{Le thème chez les Juifs}

La dernière équivalence biblique fut celle entre Rome et Ésaü ou Édom. Ésaü, frère de Jacob-Israël, parfois désigné sous les noms d'Édom ${ }^{36}$ et de Seïr, fut la principale manière juive de désigner Rome $^{37}$. Cette équivalence est différente des précédentes, car elle intègre Rome à l'histoire biblique de manière particulière, non en faisant de Rome un ennemi extérieur à Israël, comme les Kittim, Babylone ou Tyr, mais en la transformant en un ennemi intime, un ennemi jumeau relevant de l'histoire providentielle divine. Dans cette perspective, l'histoire des derniers siècles du monde était expliquée comme une histoire judéo-romaine. Cette identification n'était pas évidente, car en supposant que les Romains étaient des descendants de Sem, elle allait contre l'idée des Romains comme

35. Voir les références dans M. Hadas-Lebel, Jérusalem contre Rome, p. 450, note 34 .

36. Sur le statut d'Édom dans la Bible et son association avec Ésaü, voir Diana Vikander Edelman, You shall not abhor an Edomite for he is your brother. Edom and Seir in History and Tradition, Atlanta, Ga., Scholars Press, 1995 ; Elie Assis, «Why Edom? On the Hostility towards Jacob's Brother in Prophetic Sources », Vetus Testamentum 56/1, 2006, p. 1-20 ; et Bradford A. Anderson, Brotherhood and Inheritance: A Canonical Reading of the Esau and Edom Traditions, London, T.\&T. Clark, 2011. Le statut d'Édom, plutôt positif dans Genèse et Deutéronome, est ensuite devenu négatif dans la tradition prophétique.

37. On trouve l'essentiel des références sur Ésaü comme surnom de Rome dans Klaus Thraede, «Iacob und Esau », Reallexicon für Antike und Christentum 16, Stuttgart, 1994, col. 1131-1132. Pour une présentation rapide du thème, Gerhard Langer, «Esau, Rom und die Geschichte der Welt », Esau-Bruder und Feind, dir. Gerhard Langer, Göttingen, Vandenhoeck \& Ruprecht, 2009, p. 95-102. 
peuple japhétique, que l'on retrouve dans les misdrashim de Genèse $10^{38}$ et qui avait été conservée dans l'équivalence entre Rome et les Kittim. La distorsion entre les données de la signification rabbinique et les données de la tradition biblique est ici très forte, à la mesure du choc de l'échec des révoltes juives contre Rome.

Comme le montrent les articles de Katell Berthelot et de Matthias Morgenstern dans ce même dossier, les questions relatives à la datation des traditions juives de l'identification entre Rome et Ésaü/ Édom sont loin d'être réglées. Les premiers rapprochements entre

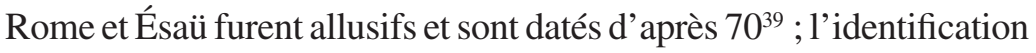
est plus clairement exprimée chez Flavius Josèphe ${ }^{40}$. L'équivalence explicite entre Rome et Ésaü apparaîtrait au début du II ${ }^{\mathrm{e}}$ siècle, peutêtre dans le cercle de rabbi Aqiba, et elle devient courante après 135, dans la tradition rabbinique rassemblée ensuite (vers 400) dans Genèse Rabbah ${ }^{41}$. Même si on doute de l'authenticité et de la datation des matériaux rassemblés dans ce dernier ouvrage, l'existence des autres textes atteste que le lien entre Rome et Ésaü existait bien à la fin du $\mathrm{I}^{\mathrm{er}}$ siècle de notre ère. L'insistance sur le thème de la fraternité biblique (attestée seulement dans Genèse et dans Abdias $^{42}$ ) visait alors à expliquer ce que les Juifs interprétaient comme une haine constante de Rome envers eux en lui donnant une origine lointaine et scripturaire. Dans les textes postérieurs au II ${ }^{\mathrm{e}}$ siècle, l'image d'Ésaü fut systématiquement noircie par l'accumulation de tous les vices par ailleurs prêtés à Rome (idolâtrie, cupidité, hypocrisie, débauche,

38. Mais cette description généalogique pouvait être neutralisée: dans le Yosippon 1.2, Zepho, petit-fils d'Ésaü accompagne Énée en Italie, devient roi des Kittim et a comme petit-fils Latinus, ancêtre de Romulus. Le texte date de 953, mais a pu s'inspirer de récits antérieurs.

39. IV Esdras VI, 8-10 (vers 100).

40. Ce dernier minimise aussi bien les aspects potentiellement négatifs (aux yeux des Grecs et des Romains) de Jacob que les dimensions négatives (selon la tradition juive) d'Ésaü (le fait d'avoir des cheveux roux, interprété comme signe de propension à la cruauté par les Juifs, voire comme signe de destination à l'esclavage par les Romains). Cela lui permet d'abord de romaniser Ésaü (en insistant sur sa pietas et sa vaillance) et d'insister sur la réconciliation des deux frères, et donc sur celle entre Juifs et Romains : voir Louis H. Feldman, « Josephus' Portrait of Jacob », The Jewish Quarterly Review, 79/2-3, 1988-1989, p. 101-151.

41. Genèse Rabbah 63.7 ; 65.21 (attribué à Juda b. 'Ilaï) ; 67.7 (attribué à José b. Halafta).

42. Bert Dicou, Edom, Israel's Brother and Antagonist: The Role of Edom in Biblical Prophecy and Story, Sheffield, JSOT Press, 1994. 
cruauté $)^{43}$. L'équivalence entre Rome et Édom serait également à mettre en relation avec l'enseignement d'Aqiba ${ }^{44}$ au début du $\mathrm{II}^{\mathrm{e}}$ siècle de notre ère ${ }^{45}$ et ne semble pas liée au statut d'Hérode, roi d'origine iduméenne et citoyen romain, car les Judéens iduméens participèrent à la révolte de 66 contre Rome. Mais la datation reste discutée et certains pensent qu'il n'y a pas eu de lien entre Édom et Rome (alors jugée chrétienne) avant le $\mathrm{IV}^{\mathrm{e}}$ siècle $^{46}$. On retrouve plus particulièrement ce lien entre Rome et Édom dans les commentaires sur les quatre empires du Livre de Daniel ${ }^{47}$.

Le problème principal des rabbins était d'expliquer pourquoi les Romains dominaient les Juifs. La justification de cette situation se trouvait dans l'idée qu'Ésaü avait eu certaines qualités (dont sa piété filiale et sa vaillance) et Jacob certains défauts (crainte de son frère, infidélité de sa descendance). Ceci permettait, peutêtre depuis Aqiba, de préserver l'idée d'une juste rétribution divine : Yahvé châtiait les bons en ce monde pour leur réserver une récompense à la fin des temps et dans le monde futur, alors que les mauvais recevaient ici-bas leur récompense avant d'être punis

43. Une précision originale du Targum Pseudo-Jonathan signale qu'Ésaü offrit de la viande de chien à son père Isaac. Ceci n'a de sens que parce que les Romains sacrifiaient des chiens lors de certains rituels. En particulier, lors des Robigalia, les animaux étaient roux; or Édom signifiait également roux/rouge : voir Robert Hayward, «Targum Pseudo-Jonathan to Genesis 27:31 », The Jewish Quarterly Review 84/2-3, 1993-1994, p. 177-188. Ce genre de remarques n'a pu être faite qu'avant l'interdiction des cultes païens, au plus tard en 391-392. La mention précise de rituels païens pourrait être une voie d'approche vers la datation des textes rabbiniques; voir Emmanuel Friedheim, Rabbinisme et paganisme en Palestine romaine: étude historique des Realia talmudiques (Irr-Ve siècles), Leiden, Brill, 2006.

44. M. Hadas-Lebel, Jérusalem contre Rome, p. 470. Voir aussi Yves-Marie Duval, « Jérôme et les prophètes. Histoire, prophétie, actualité et actualisation dans les commentaires de Nahum, Michée, Abdias et Joel », Congress Volume Salamanca 1983, dir. John A. Emerton, Leiden, Brill (Supplements to Vetus Testamentum 36), 1985, p. 108-131, en particulier p. 122, note 87.

45. Voire même dès le $\mathrm{I}^{\text {er }}$ siècle de notre ère selon André Lemaire, «D'Édom à l'Idumée et à Rome ", Antiquités Sémitiques II, Des Sumériens aux Romains d'Orient. La perception géographique $d u$ monde, Paris, Jean Maisonneuve - Librairie d'Amérique et d'Orient, 1997, p. 81-103, spécialement p. 100, note 144.

46. Jacob Neusner, Persia and Rome in Classical Judaism, Lanham, University Press of America, 1984.

47. Hermann L. Strack et Paul Billerbeck, Kommentar zum neuen Testament aus Talmud und Midrasch, IV.2, Exkurse zu einzelnen Stellen des Neuen Testaments : Abhandlungen zur neutestamentlichen Theologie und Archäologie, München, C. H. Beck, 1928, p. 1004-1006. 
ensuite $^{48}$. Au total, la relation de frères ennemis entre Ésaü et Jacob ne fut pas posée de manière historique ${ }^{49}$ mais de façon mythique et symbolique. Néanmoins, le thème de la fraternité ennemie permettait de mettre le conflit entre Rome et les Juifs au centre de l'histoire par la projection du présent des années 70-135 sur un passé patriarcal. Ceci expliquerait la fixation des rabbins sur Ésaü - Édom au détriment des autres ennemis bibliques d'Israël et de Juda ${ }^{50}$.

Cette exégèse pouvait être utilisée pour rapprocher Juifs et Romains (comme chez Josèphe), mais servit surtout à insister sur la haine ancestrale entre les deux peuples et sur la victoire à venir d'Israël sur Rome (chez les rabbins des II $^{\mathrm{e}}$-III ${ }^{\mathrm{e}}$ siècles). Mais comme Rome était reconnue comme le quatrième et dernier empire, l'avenir serait eschatologique et messianique plus que strictement historique et politique. Cependant, en lisant Daniel, certains rabbins développèrent l'idée que le royaume messianique d'Isräll serait l'héritier de l'empire romain, Jacob reprenant alors ce qui avait été donné à Ésaü ${ }^{51}$.

\section{Le thème chez les chrétiens}

Dans la tradition chrétienne, il faut distinguer l'opposition entre Jacob et Ésaü, qui est banale, et l'identification entre Rome et Ésaü, qui est rare. La première était déjà présente chez Paul de Tarse (Romains 9, 11-13 sur l'élection divine). Chez les Grecs et les Latins des $\mathrm{III}^{\mathrm{e}}$ et $\mathrm{IV}^{\mathrm{e}}$ siècles, la rivalité entre les deux frères fut comprise comme l'opposition entre l'Église (dernière née) et la Synagogue (première née), les chrétiens étant le Verus Israel. Cette exégèse est attestée dès le $\mathrm{II}^{\mathrm{e}}$ siècle, dans l'Épître de Barnabé et chez Irénée de Lyon, puis ensuite chez Tertullien et Origène ${ }^{52}$. Elle

48. On trouve également une justification de la rétribution terrestre de Rome chez Augustin : la uirtus supérieure des anciens Romains, qui leur permit de maîtriser les vices des humains, amena Dieu à leur accorder la domination sur les autres peuples ; voir H. Inglebert, Les Romains chrétiens face à l'histoire de Rome, p. 482-484.

49. Cela aurait posé le problème d'une Rome d'ascendance sémitique, comme chez Aphraate (voir ci-dessous). Le thème fut néanmoins abordé car, outre le Josippon, on le trouve dans la tradition éthiopienne du Kebra Nagast (début XIV $V^{\mathrm{e}}$ siècle); mais les éléments antérieurs ne sont pas mieux datés que les traditions rabbiniques.

50. M. Hadas-Lebel, Jérusalem contre Rome, p. 472-473.

51. Alexei M. Sivertsev, Judaism and Imperial Ideology in Late Antiquity, Chicago, Cambridge University Press, 2011, p. 9-44.

52. Tertullien, Ad Marcionem III.24.9 et De anima 26.2. Origène, Homélies sur la Genèse 2.3. 
fut ensuite dominante durant des siècles ${ }^{53}$. On pouvait la compléter par une autre lecture, morale celle-là et déjà attestée chez Philon, qui opposait la vertu, symbolisée par Jacob, et le vice incarné par Ésaü. Cette typologie, attestée chez Clément d'Alexandrie et Origène, pouvait être appliquée aux bons et mauvais chrétiens, et fut adaptée à divers contextes, comme ceux des crises arienne (Athanase), donatiste ou pélagienne (Augustin) ${ }^{54}$.

Le thème de l'équivalence entre Rome et Ésaü chez les chrétiens est un problème complexe, qu'il faut analyser par aire culturelle. Cette analyse est nécessairement liée à une autre question, celle des relations entre les auteurs chrétiens et les rabbins. Les deux questions étant mêlées, il convient d'être attentif afin d'éviter des raisonnements circulaires.

Chez les auteurs chrétiens grecs, le lien entre Rome et Ésaü ou entre Rome et Édom ne semble guère avoir été traité, ni dans les commentaires sur Isaïe ${ }^{55}$, ni dans ceux sur les petits prophètes ${ }^{56}$. Néanmoins, on ne peut être absolument catégorique car de très nombreuses œuvres ont disparu ou sont incomplètes.

53. L. Feldman, «Josephus' Portrait of Jacob», p 120, note 45, suppose que l'identification de Jacob à l'Église et d'Ésaü aux Juifs a pu amener certains rabbins à réhabiliter Ésaü.

54. Voir les références chez Göran Larsson, « Jakob/Jakobsegen » Theologische Realenzyklopädie XVI, p. 466-468, particulièrement p. 467, « Jakob als Symbol »; K. Thraede, «Iacob und Esau », Reallexicon für Antike und Christentum 16, col. 1151-1152 sur Ésaü chez Origène, 1156 chez Athanase, 1168 chez Tertullien et 1181-1182 chez Jérôme. On trouve des analyses détaillées chez Marine Dulaey, « Jacob dans l'exégèse paléochrétienne (Gn 27-33) », Recherches Augustiniennes 32,2001 , p. 75-168, principalement 81-85, 100-106 et 144-145 ; voir aussi Gérard Nauroy, «Formes de l'exégèse pastorale chez Ambroise et Augustin. Deux lectures de la rivalité entre Jacob et Ésaü », Saint Augustin et la Bible, dir. G. Nauroy et M. A. Vannier, Bern, Peter Lang, 2008, p. 83-104.

55. On ne trouve rien sur le sujet chez Origène dans les fragments conservés sur la Genèse et dans les homélies sur Isaïe traduites par Jérôme (GCS 33), chez Eusèbe de Césarée dans l'Onomasticon et dans son Commentaire sur Isaïe (écrit après 316, sans doute entre 320 et 330), chez le Pseudo-Basile (ou chez Basile de Césarée) dans son Commentaire sur Isaïe (PG 30, 117-668), chez Jean Chrysostome (Commentaire sur Isaïe, SC 304 ; avant 386), chez Cyrille d'Alexandrie (PG 70 ; avant 429) ; chez Théodoret de Cyr (Commentaire sur Isaïe, SC 276, 295, 315 ; Questions sur l'Octateuque).

56. Didyme d'Alexandrie (Commentaire sur Zacharie, vers 387), Théodore de Mopsueste (Commentaire sur les douze prophètes; vers 380), Cyrille d'Alexandrie (Commentaire sur les douze prophètes ; vers 420), Théodoret de Cyr (Commentaire sur les douze prophètes, vers 430). 


\section{Aphraate}

Dans la sphère syriaque, on dispose en revanche d'un texte attribué au «sage persan », que l'on appela ensuite Aphraate. Ce texte est particulièrement important pour notre sujet, car il est clair et bien daté, ce qui n'est pas le cas des sources rabbiniques. Aphraate vivait dans l'empire perse sassanide et écrivit en 337 un memré, un texte poétique, sur la guerre qui semblait sur le point d'éclater entre Constantin et Shapour II. La mort de l'empereur romain devait repousser le conflit de quelques années, mais en 337 , Aphraate était confiant dans l'issue de la guerre à venir, et rassurait ses coreligionnaires en affirmant que le roi des rois sassanide ne pourrait vaincre l'empereur chrétien. Il avançait deux arguments principaux. Le premier était historique et s'appuyait sur une des visions de Daniel, celle des quatre animaux : puisque l'empire achéménide avait été vaincu par Alexandre, celui des Sassanides, descendant de l'empire perse de jadis, serait logiquement battu par les Romains, héritiers du Macédonien ${ }^{57}$; ce que Dieu avait voulu jadis se répéterait au présent. Cette exégèse de Daniel fondée sur le parallèle entre les deux empires perses achéménide et sassanide lui est sans doute propre ${ }^{58}$. Le second argument était théologique, établissant une série de relations entre Dieu, les Juifs, les chrétiens, les Romains et les Perses, comme le montre le texte suivant:

22 : Or, donc, une vigne a remplacé la vigne, et lors de sa venue, Il a aussi livré le royaume aux Romains qu'on appelle fils d'Ésaü. Et ce sont les fils d'Ésaü qui gardent le royaume pour Celui qui le leur a donné.

23 : Mais c'est d'un royaume éternel qu'héritera le peuple saint qui a été choisi à la place du peuple

[...] De la sorte, quand viendra Celui qui abolit le royaume, Il viendra chez eux sans colère.

En effet, quand viendra à sa seconde venue Celui à qui appartient le royaume, Il prendra ce qu'Il a donné, Il sera roi pour les siècles des siècles, et son royaume ne passera pas, car c'est un royaume éternel.

24 : En effet, Il avait d'abord donné le royaume aux fils de Jacob, et Il leur avait asservi les fils d'Ésaü, ainsi qu'Isaac le dit à Ésaü : « Tu serviras ton frère ».

57. Exposé 5, Des guerres 15-19.

58. De même que l'était son insistance sur les Séleucides et non sur les Lagides à propos de l'époque des successeurs d'Alexandre, Exposé 5, Des guerres 19. Voir H. Inglebert, "Aphraate, le "sage persan" : la première historiographie syriaque », Syria 78 (2001), p. 179-208. 
Comme ils n'ont pas réussi dans leur royaume, Il l'a repris aux fils de Jacob et Il l'a donné aux fils d'Ésaü jusqu'à ce que vienne Celui à qui il appartient.

Ils rendront le dépôt à Celui qui l'a donné sans en rien retenir ; celui qui a gardé le royaume se soumettra à Celui à qui tout est soumis.

Voilà pourquoi ce royaume des fils d'Ésaü ne sera pas livré aux mains des armées rassemblées qui veulent monter contre lui parce que ce royaume est gardé par Celui qui l'a donné et c'est Lui qui le garde.

Et puisque je t'ai écrit, mon ami, que le royaume des fils d'Ésaü sera gardé pour Celui qui l'a donné, n'aie aucun doute : ce royaume ne sera pas vaincu.

Car l'homme vaillant dont le nom est Jésus va venir avec l'armée, et ses armes, toute l'armée du royaume va les porter. Scrute et vois : il est inscrit avec eux dans le recensement, et, de même qu'il est inscrit avec eux dans le recensement, il va les aider. Son signe s'est multiplié en ce lieu, ils ont revêtu ses armes et ne seront pas défaits à la guerre.

Mais peut-être me diras-tu : «Pourquoi dans les années des rois précédents, ceux-ci furent-ils vaincus par la bête et asservis ?». C'est que les chefs et les rois qui se levèrent en ce temps-là sur le royaume des fils d'Ésaü n'ont pas voulu emmener avec eux à la guerre l'homme qui était inscrit avec eux dans le recensement. C'est pour cela que la bête a été quelque peu soumise, mais elle n'a pas été tuée. ${ }^{59}$

Ce texte intègre des éléments juifs, chrétiens, et constantiniens. Ces derniers sont présents dans le thème du Christ combattant désormais avec les Romains. En parlant du signe du Christ qui s'est multiplié chez eux, Aphraate faisait allusion au fait que les armées romaines arboraient le signe du Christ - le chrisme ou le labarum comme emblème. De même, il supposait que Jésus avait été enregistré comme citoyen romain lors du recensement de Quirinius. On retrouve chez Aphraate, comme chez l'auteur du Commentaire sur Daniel (vers 200, attribué à « Hippolyte de Rome ${ }^{60} »$ ) le lien entre la citoyenneté romaine, le recensement de Bethléem et la guerre, mais désormais avec une signification inversée. En effet, Aphraate pensait que le Christ avait été Romain, anachronisme que seule la citoyenneté devenue universelle depuis 212 permettait, et, de plus, qu'il était devenu le protecteur des armées romaines ${ }^{61}$, ce

59. Exposé 5, Des guerres 22-24 ; Sources chrétiennes $n^{\circ}$ 349, p. 354-356 (traduction Marie-Joseph Pierre).

60. Pour une mise au point sur les attributions des textes à Hippolyte de Rome, voir Gabriella Aragione et Enrico Norelli (dir.), Des évêques, des écoles et des hérétiques, Lausanne, Édition du Zèbre, 2011.

61. Bien entendu, cette protection n'existait pas du temps des empereurs païens (« les rois précédents », ce qui permet à Aphraate de justifier, à la fin du paragraphe 24, les défaites des Romains face à Shapour I ${ }^{\mathrm{er}}$, en 241 (prise d'Hatra), 244 (à Misikhé, 
que seule l'existence d'un empereur romain chrétien, Constantin, rendait possible. Le thème de la protection des armées romaines par le Christ, le fait que l'empereur chrétien soit Victor et l'utilisation du signe du Christ par les armées romaines sont constantiniens. Ils étaient connus en Orient par la lettre de Constantin à Shapour II, qui datait sans doute de $324-325^{62}$. Quant au thème de la citoyenneté romaine de Jésus, cela peut être une argumentation chrétienne grecque d'époque constantinienne, qui répondait à celle du Commentaire sur Daniel, et qui rendait positif le lien entre être Romain, être chrétien et aller à la guerre. Mais nous n'avons pas conservé de texte grec exprimant cela de manière aussi nette.

Si l'on compare le texte d'Aphraate avec la tradition juive, on constate qu'il en reprend les éléments factuels : la vigne du Seigneur pour désigner le peuple choisi, la puissance temporelle des fils d'Ésaü qui renvoie à l'empire des Romains, et le fait que Rome soit le dernier pouvoir terrestre, le royaume messianique éternel étant à venir. Mais il réinterprète tout cela dans un sens chrétien, avec le thème du Verus Israel (22: «une vigne a remplacé la vigne »; 23 : « le peuple saint qui a été choisi à la place du peuple»). Il faut surtout noter que l'empire romain est le gardien de la royauté universelle messianique, ce pourquoi il ne peut être vaincu puisqu'il est protégé par le Christ. On retrouve là l'idée d'un lien particulier entre Rome et le christianisme, lié à la naissance de Jésus de Nazareth sous Auguste, déjà attesté chez Méliton de Sardes (vers 180, pour qui la paix romaine était en réalité la paix messianique ${ }^{63}$ ) et surtout chez Origène (vers 249, pour qui Dieu avait voulu l'empire romain afin de favoriser l'expansion de la doctrine

combat qui provoqua la mort de Gordien III), en 252-253 (défaite de Barbalissos et dévastation de la Syrie), 256 (destruction de Doura Europos) et 260 (capture de Valérien près d'Édesse, dévastation de l'Anatolie orientale et de la Syrie du Nord).

62. Cette lettre écrite en latin avait été traduite en grec pour être comprise de tous, et nous est connue par Eusèbe de Césarée, Vie de Constantin 4.9-13. Aphraate a pu dans Des guerres 24, s'inspirer des deux passages suivants : "Mon armée, consacrée à Dieu, porte son signe (le chrisme ou le labarum) sur ses épaules »; et « Je pense à l'un d'eux, que la colère divine comme un coup de foudre, a chassé d'ici et livré à vos régions, avec pour conséquence ce fameux trophée de sa honte que l'on voit chez vous » (allusion à la défaite et la captivité de Valérien en 260 face aux Perses). Éphrem, Hymnes sur la Nativité 18.3, fait allusion à Constantin en mentionnant "la royauté qui a arboré Sa croix : béni soit celui qui l'a exalté ». Et il mentionne le Christ en liesse au milieu de la solennité de la fête de la Nativité, « comme un commandeur d'armée », Hymnes sur la Nativité 5.12.

63. Méliton de Sardes, Apologie, citée dans Eusèbe de Césarée, Histoire ecclésiastique IV.26.6-7. 
chrétienne $\left.{ }^{64}\right)$. Cependant, le lien entre christianisme et domination universelle faisant du monothéisme et de la monarchie romaine les deux aspects d'un même projet divin contre le polythéisme et la polyarchie afin d'imposer la vérité divine et la paix christique, ne fut pleinement affirmé que par Eusèbe de Césarée ${ }^{65}$ vers 310-325. En affirmant que le Christ avait confié la royauté messianique aux Romains à sa naissance ou à sa résurrection jusqu'à la Parousie (la seconde venue), Aphraate montrait, en le présentant de manière personnelle, qu'il était au courant des développements idéologiques récents de l'empire chrétien. Mais on savait en Perse que Constantin avait réuni le concile de Nicée (325) auquel avait participé un évêque de la Mésopotamie perse. Cet empire du Christ géré par les fils d'Ésaü et protégé par Lui explique la précision selon laquelle le messie parousiaque « viendra chez eux sans colère » (22) pour établir sa royauté éternelle, par une transmutation spirituelle du pouvoir terrestre universel de Rome. Enfin, il faut remarquer que la relation entre Jacob et Ésaü n'est pas d'ordre typologique, où les Romains seraient les fils d'Ésaü et les chrétiens les fils de Jacob, promis à un meilleur avenir. La présentation est chronologique avec les fils de Jacob qui sont bien les Juifs, dont le royaume donné par Dieu leur a été repris pour être donné aux fils d'Ésaü par le Christ. Tout au plus, l'idée d'un nouveau peuple saint pourrait par le passage du véritable Israël conduire aux chrétiens comme véritables fils de Jacob, mais un tel développement ne se trouve pas chez Aphraate.

En revanche, on trouve chez lui une distinction importante entre Ésaü et les fils d'Ésaü. En effet, Aphraate mentionne trois fois Ésaü comme celui qui se vante aux dépens de Jacob et qui ensuite est abaissé, en perdant son droit d'aînesse et sa bénédiction ${ }^{66}$. Ce n'est alors là qu'un exemple biblique parmi d'autres afin de condamner l'orgueil face à l'humilité. Cependant, cela distingue non seulement Ésaü et les Romains, fils d'Ésaü, par une différence chronologique, mais cela permet également de fonder une différence de qualité entre Ésaü, personnage négatif, et les fils d'Ésaü, présentés positivement, politiquement ${ }^{67}$ mais surtout religieusement, puisque le Christ leur

64. Contre Celse II.30.

65. Préparation évangélique I.4.1-6 et V.1.4-6.

66. Exposé 5, Des guerres 3; Exposé 9, De l'humilité 8 ; Exposé 14, Des arguments 40.

67. Une autre supériorité des fils d'Ésaü réside en effet dans leurs institutions, Exposé 5, Des guerres 13. 
a confié la garde du royaume universel et qu'ils sont eux-mêmes devenus chrétiens. Mais cette origine biblique des Romains a chez Aphraate des conséquences sur leur appartenance ethnique. En effet :

Car, quand les fils de Japhet prirent le royaume, ils tuèrent Darius, le roi de Perse.

Maintenant, la quatrième bête a avalé la troisième. Cette troisième, ce sont les fils de Japhet, et la quatrième, ce sont les fils de Sem, qui sont les fils d'Ésaü.

Car quand Daniel vit la vision des quatre bêtes, il vit d'abord celle des fils de Cham, descendants de Nemrod, c'est-à-dire les Babyloniens. En second lieu, celle des Perses et des Mèdes, qui sont des fils de Japhet. En troisième lieu, celle des Grecs, frères des Mèdes, et en quatrième lieu, celle des fils de Sem, qui sont fils d'Ésaü.

En effet, il y eut une association entre les fils de Japhet et les fils de Sem, et le gouvernement fut ôté aux fils de Japhet le cadet et donné à Sem l'aîné, et il en sera ainsi jusqu'à aujourd'hui et jusqu'à toujours.

Mais quand sera venu le temps de la fin du gouvernement des fils de Sem, le chef sorti des fils de Juda recevra la royauté quand il viendra pour son second avènement. ${ }^{68}$

Dans ce texte, Aphraate analyse la succession des quatre empires, selon l'interprétation dominante chez les Juifs et les chrétiens romains : Babyloniens depuis Nemrod (en fait Assyriens/Néo-Babyloniens), Perses et Mèdes, Grecs (Macédoniens) et Romains. Il les relie de manière originale aux trois fils de Noé, faisant des Babyloniens des descendants de Cham, des Perses, Mèdes et Grecs des descendants de Japhet et des Romains des descendants de Sem. En fait, la première et la troisième interprétation ne sont pas conformes aux équivalences midrashiques de Genèse 10, où les Babyloniens sont comptés comme sémitiques et les Romains comme japhétiques. C'est sans doute pour cela qu'il ne semble pas qu'on la retrouve chez les Juifs. Néanmoins, pour Aphraate, la filiation entre les Romains et Ésaï n'était pas de l'ordre du symbolique, mais relevait bien de la généalogie: les Romains étaient réellement les fils d'Ésaü et donc les lointains cousins des Juifs, et tous étaient des descendants de Sem ${ }^{69}$. Enfin, l'association entre les fils de Japhet et les fils de Sem renvoie à une autre idée selon laquelle l'empire de Rome prolonge en réalité celui d'Alexandre

68. Exposé 5, Des guerres 10 ; Sources chrétiennes $\mathrm{n}^{\circ} 349$, p. 336-337 (traduction Marie-Joseph Pierre).

69. Selon un raisonnement proche de celui sur la parenté des Juifs et des Spartiates à partir d'Abraham que l'on trouve mentionnée en 1 Maccabées 12, 20-23. 
contre le royaume oriental des Perses ou des Parthes, théorie renforcée par l'utilisation de l'ère d'Alexandre par les chrétiens syriaques, qui donnait une impression de continuité temporelle ${ }^{70}$.

Il faut tout de même noter que cette volonté d'historicisation/ ethnicisation des Romains et de cohérence entre les thèmes des quatre empires et des trois fils de Noé semble s'opposer au schéma présenté plus haut (Des guerres 24) selon lequel :

Il avait d'abord donné le royaume aux fils de Jacob, et Il leur avait asservi les fils d'Ésaü, ainsi qu'Isaac le dit à Ésaü : «Tu serviras ton frère $»$.

Comme ils n'ont pas réussi dans leur royaume, Il l'a repris aux fils de Jacob et Il l'a donné aux fils d'Ésaü jusqu'à ce que vienne Celui à qui il appartient.

Or, on ne peut avoir les Romains succédant en même temps aux Grecs et aux Juifs. Pour résoudre la contradiction, il faut supposer que l'on ne parle pas du même royaume dans les deux passages. Dans Des guerres 10, il s'agit du royaume terrestre universel, que les Romains ont pris aux Grecs (les Séleucides pour Aphraate). Dans Des guerres 24, Aphraate parle du royaume terrestre de Dieu, d'abord représenté par les Juifs, puis par les Romains (alors le quatrième empire) et désormais par le pouvoir romain chrétien. Et les deux passages furent décalés dans le temps, avec l'accession des Romains au rang de quatrième empire de Daniel lors de la fin des Séleucides, puis la promotion de ce quatrième empire comme gardien du Royaume divin par le Christ, soit lors de la Nativité, soit lors de l'Ascension. Cela permet de légitimer le pouvoir des Romains d'un point de vue naturel et familial, à la fois comme fils de Sem (aîné de Japhet, contre les Grecs) et comme fils d'Ésaï (aîné de Jacob, contre les Juifs).

En conclusion, l'Exposé 5, Des guerres, d'Aphraate est un texte tout à fait original. Aphraate témoigne d'une culture commune araméenne avec les Juifs mésopotamiens de son temps ${ }^{71}$, tout en intégrant des éléments historiques ou politiques venus de l'Orient romain chrétien. Son acceptation des Romains comme «fils d'Ésaü» est d'origine juive. Elle n'a pas de précédent dans la première version de la Caverne

70. Hervé Inglebert, Interpretatio Christiana. Les mutations des savoirs (cosmographie, géographie, ethnographie, histoire) dans l'Antiquité chrétienne (30-630 après J.-C.), Paris, Institut d'Études Augustiniennes, 2001, p. 352-358.

71. Jacob Neusner, Aphrahat and Judaism: The Christian-Jewish Argument in Fourth-Century Iran, Leiden, Brill, 1971 ;Eliyahu Lizorkin, Aphrahat's Demonstrations: A Conversation with the Jews of Mesopotamia, Louvain, Peeters, 2012. 
des Trésors, ni de parallèle chez Éphrem, qui fit principalement une lecture historique des prophéties contre Édom. Mais surtout, le texte d'Aphraate prouve que le thème des Romains comme fils d'Ésaü, qu'il présente comme une évidence qu'il n'est pas besoin de justifier ni d'expliquer, était alors une idée banale, qui ne peut provenir que du judaïsme babylonien de l'époque. Comme il écrit vers 337, cela est un indice pour supposer que le thème était courant depuis au moins le début du IV siècle, soit un siècle avant la compilation de Genèse Rabbah.

\section{Augustin}

Chez les chrétiens latins, dans les années 350-630, il existe une vingtaine de mentions des fils d'Ésaü. Mais là aussi, il faut distinguer les aspects exégétiques ou théologiques et le lien avec Rome. Augustin fait une analyse en deux temps. En De civitate Dei XVI.35, il comprend «l'aîné sera soumis au plus jeune » de deux manières : l'une historique : les Juifs ont soumis les Iduméens ; l'autre théologique et préférable: le peuple juif sera le serviteur du peuple chrétien. Mais il admet ensuite en XVI.42 que du point de vue charnel, ce sont les Iduméens qui descendent d'Ésaü, et non les Juifs, et que ce ne sont pas les chrétiens, mais les Juifs, qui descendent de $\mathrm{Jacob}^{72}$, et qu'il faut donc distinguer la typologie et la généalogie, qui sont en fait contradictoires. De son côté, Jérôme reprend le rapprochement biblique entre les fils d'Ésaü, Édom et Seir $^{73}$, suivi ensuite par Isidore de Séville ${ }^{74}$ et Bède le Vénérable ${ }^{75}$. Mais tous ces textes ne font aucun rapprochement avec Rome.

72. De ciuitate Dei XVI.42: «sicut autem duo Isaac filii, Esau et Iacob, figuram praebuerunt duorum populorum in Iudaeis et Christianis (quamuis, quod ad carnis propaginem pertinet, nec Iudaei uenerint de semine Esau, sed Idumaei; nec Christianae gentes de Iacob, sed potius Iudaei; ad hoc enim tantum figura ualuit, quod dictum est: maior seruiet minori): ita factum est etiam in duobus filiis Ioseph; nam maior gessit typum Iudaeorum, Christianorum autem minor ». Voir Rainer Kampling, «' ... fast niemand von den Unsrigen versteht das anders' (Civ. D. 16,35). Esau bei den lateinischen Kirschenschriftsteller», Esau - Bruder und Feind, dir. Gerhard Langer, Göttingen, Vandenhoeck \& Ruprecht, 2009, p. 243-252.

73. Liber quaestionum hebraicarum in Genesim, qui reprend Vulgate Genèse 36,19 : « isti filii Esau et hii duces eorum ipse est Edom ». On peut en rapprocher Arnobe le Jeune, Commentarii in Psalmos, Psalmus 136: «Memento, domine, filiorum Edom, id est filiorum Esau ».

74. Etymologiarum siue Originum libri $X X: 9.2 .9$ : «Edom filius Esau, a quo Idumaei ».

75. In principium Genesis usque ad natiuitatem Isaac... 3.14 : « Isti filii Esau et hi duces eorum; ipse est Edom ». 


\section{Jérôme}

En fait, on ne dispose sur le sujet de l'équivalence Rome/Ésaü/ Édom que de quelques textes exégétiques de Jérôme, qui affirme parfois rapporter des opinions juives. Il n'y a pas de raison de douter de cela, car les interprétations sont négatives envers Rome, affirmant la destruction future de son empire au profit d'IsraëlJacob. Le véritable problème est de savoir d'où Jérôme tient ses informations, qui peuvent lui venir soit de commentateurs grecs antérieurs, soit d'informateurs juifs contemporains. On sait en effet que Jérôme a appris l'hébreu auprès de plusieurs personnes ${ }^{76}$ et qu'il consultait régulièrement des spécialistes juifs de la Bible en Galilée, qui étaient sans doute proches des traditions rabbiniques ${ }^{77}$.

Dans les préfaces de ses commentaires sur les petits prophètes ${ }^{78}$, Jérôme distingua ceux qui avaient recours à l'exégèse allégorique (Origène, Didyme d'Alexandrie) et ceux qui préféraient l'exégèse historique (il ne nomme personne, mais cela peut désigner Eusèbe de Césarée, qu'il cite ailleurs dans son texte; il ne s'agit sans doute pas de Théodore de Mopsueste, contemporain de Jérôme, car ce dernier ne le mentionne jamais et il ne connaissait sans doute pas son œuvre, car il ne s'en inspire pas ${ }^{79}$ ). Il lui arrive

76. Sur le problème, fort discuté depuis longtemps, des compétences de Jérôme en hébreu, voir les articles de Roger Gryson, « Saint Jérôme traducteur d'Isaïe. Réflexions sur le texte d'Isaïe 14, 18-21 dans la Vulgate et dans l'In Isaiam », Le Museon 104, 1991, p. 57-72, et de Stefan Rebenich, «Jerome: the 'Vir trilinguis' and the 'Hebraica veritas' », Vigiliae Christianae 47, 1993, p. 50-77.

77. On en a un exemple en In Abdiam 20-21 : « Ubi nos posuimus Bosphorum, in Hebraico habet Sapharad, quod nescio cur Septuaginta Ephrata transferre potuerint, cum et Aquila, et Symmachus, et Theodotio cum Hebraica ueritas concordent. Nos autem ab Hebraeo, qui nos in scripturis erudiuit, didicimus Bosphorum sic uocari ; et quasi Iudaeus, ista inquit, est regio, ad quam Hadrianus captiuos transtulit ».

78. Jérôme mentionne ses prédécesseurs dans les prologues de In Zachariam (Origène, Hippolyte et Didyme, avec une exégèse allégorique), de In Malachiam (Origène, allégorique, et Apollinaire de Laodicée, ponctuel et fort bref) et In Osee (Apollinaire de Laodicée, Origène, Pierus d'Alexandrie, Eusèbe de Césarée dans la Préparationévangélique, Didyme). À propos des traductions de ces textes prophétiques, on trouvera une série d'articles sur le sujet dans le dossier «L'interpretazione dei Profeti tra la LXX e Gerolamo », Adamantius 13, 2007, p. 7-125.

79. Parmi ceux qui faisaient une interprétation historique des textes prophétiques, on peut signaler également Éphrem qui interprétait Abdias 6 comme la destruction d'Édom par Nabuchodonosor, et Abdias 10 et 18 comme le fait que les Juifs avaient soumis les Édomites. Mais lui non plus n'est pas utilisé par Jérôme. 
également de citer des interprétations juives. Le problème est que dans ce cas, on sait qu'il cite parfois sans les nommer des extraits d'Origène et d'Eusèbe de Césarée renvoyant à des lectures juives ${ }^{80}$. Aussi, la principale question dans le cas des identifications hiéronymiennes entre Rome et Ésaü/Édom, que l'on trouve dans les commentaires sur Michée (393), Abdias (396), Joël (396), Malachie (406) et Isaïe (408-410), est de savoir si Jérôme a eu recours à un commentaire grec antérieur ou à un informateur juif contemporain.

Origène avait écrit un commentaire sur les petits prophètes en 25 livres, qu'Eusèbe de Césarée connaissait (mais le livre sur Abdias était déjà perdu). Le texte d'Origène a été perdu depuis, même s'il a pu inspirer Didyme d'Alexandrie sur Zacharie. Dans ses préfaces sur Michée, Abdias et Joël, Jérôme ne dit rien de ses prédécesseurs et dans le prologue de Malachie, il signale seulement Origène et Apollinaire de Laodicée ${ }^{81}$.

Le texte sur Michée ${ }^{82}$ précise que des Juifs supposent que toutes les nations serviront les Juifs, y compris l'empire romain assimilé à Édom, qui sera broyé par les cornes de fer et les sabots de bronze. Jérôme ajoute que cette interprétation est stupide, car le texte se rapporte à des événements très anciens ${ }^{83}$; il propose ensuite une lecture allégorique appliquée à l'Église.

80. Gustave Bardy, « Saint Jérôme et ses maîtres hébreux », Revue Bénédictine, 1934, p. 145-164 ; Pierre Jay, L'exégèse de Saint Jérôme d'après son commentaire sur Isaïe, Paris, Institut d'Études augustiniennes, 1985, p. 39-43; et Ilena Opelt, «San Girolamo e i suoi maestri ebrei », Augustinianum 28, 1988, p. 327-338. Jérôme fait référence à des magistri Hebraeorum dans In Ose, Prologue, ainsi qu'à des magistri Iudaeorum dans In Amos 1.1, dans In Isaiam 9.29.9 (mais pour un point de rituel) et en In Isaiam 10.34.1 ( Bosra, id est munitam atque firmatam, et Edom, siue Duma, et Idumaeam, Iudaeorum magistri Romam intellegi uolunt, et omnia de ipsa dici quae sequenti capitulo continenture), qui est le seul texte où ils interviennent en relation avec Édom.

81. In Malachiam, Prologue (ligne 46) : «scripsit in hunc librum Origenes tria uolumina, sed historiam omnino non tetigit, et more suo totus in allegoriae interpretatione uersatus est [...] alios commentarios in hunc prophetam legisse me nescio, excepto Apollinaris breui libello, cuius non tam interpretatio quam interpretationis puncta dicenda sunt $»$.

82. In Michaeam 4.13 : « Haec Iudaei necdum expleta cernentes, in futuro ibi Christi pollicentur aduentu, et dicunt uniuersas nationes Iudaico populo seruituras, ipsum que imperium Romanorum, quod sub nomine interpretantur Edom, conterendum esse ungulis suis et cornibus uentilandum ».

83. Sur les mentions des Hebraei et des Iudaei dans ce commentaire, voir Y.-M. Duval, « Jérôme et les prophètes », p. 115-118. 
Dans son commentaire sur Abdias, Jérôme cite une interprétation juive d'Isaïe selon laquelle par une modification de lettre, ce qui est dit de Duma pourrait être compris de Roma ${ }^{84}$; et on retrouve cette explication dans le commentaire sur Isaïe ${ }^{85}$. Comme il s'agit de philologie hébraïque et non grecque, il n'est pas évident de supposer une reprise d'Origène. Dans le même texte, Jérôme rejette une interprétation eschatologique juive de la prophétie ${ }^{86}$, et propose ensuite trois possibilités de lecture : historique, allégorique avec application présente à l'Église, tropologique avec une interprétation morale ${ }^{87}$.

Le texte sur Malachie ${ }^{88}$ rapporte que des Juifs se trompent en imaginant qu'à cause de l'amour divin pour Jacob et de la haine divine envers Ésaü, ils obtiendront le royaume sur le monde lors de la fin du monde ${ }^{89}$ (lors du jour de Yahvé), et de la destruction de l'empire de Rome. Jérôme dénonce cette fausse illusion, et propose ensuite une interprétation spirituelle, dont l'origine remonte à Philon et qui fut reprise par beaucoup, dont Origène, qui fait de Jacob la vertu que Dieu aime et d'Ésaü le vice que Dieu hait et rejette. On notera que ce texte est le seul texte chrétien, avec le commentaire hiéronymien sur Abdias mentionné plus haut, où l'on retrouve

84. In Abdiam 1: «Iudaei frustra somniant contra urbem Romam, regnum que Romanum hanc fieri prophetiam; et illud quod in Esaia scriptum est: onus Duma, paululum litterae apice commutato pro deleth legi posse res, et sonare Romam, uau quippe littera et pro u, et pro o, in eorum lingua accipitur ».

85. In Isaiam 21.11: « Hoc iuxta historiam dictum sit; ceterum propter similitudinem litterae, ex eo quod res et daleth non multum inter se discrepent, quidam Hebraeorum pro Duma Romam legunt, uolentes prophetiam contra regnum Romanum dirigi, friuola persuasione, qua semper in Idumaeae nomine Romanos existimant demonstrari ».

86. In Abdiam 17-18: «Quia uero Esau super fundamentum Christi uitio suo exstruxerat fenum, ligna et stipulam, idcirco domus Iacob et Ioseph in ignem uertetur et flammam [...] Et quicquid contra Idumaeam interpretati sumus, illi aduersum Romanum regnum somniant; quod nos dicimus, aut iuxta historiam sub Zorobabel esse iam factum, aut certe iuxta prophetiam, et mysticos intellectus cotidie in ecclesia fieri, et in regno animae aduersus carnem, in unoquoque compleri ».

87. Mais il ne faut pas supposer que Jérôme a une typologie exégétique toujours précise ; il peut exister divers sens spirituels; voir P. Jay, L'exégèse de Saint Jérôme, p. 330-333.

88. In Malachiam 1.2 et 1.5 : « odium igitur in Esau rebus ostendi, amorem autem in uos, hoc est in Iacob, sequentibus approbabo [...] Iudaei falso sibi blandiuntur, Edom Romanos et Israel in consummatione mundi se prophetari, quod destructo Romano imperio, hoc est Idumaeo, regnum orbis ueniat ad Iudaeos ».

89. Jérôme dénonce le même espoir en In Sophoniam II.8-11 : "Quod si iniustum est nepotibus reddere quod deliquerint aui, quanto iniustius pro stultitia Iudaeorum hoc ipsum sperare in consummatione mundi fieri ». 
clairement l'équivalence Ésaü - Édom - Rome. On remarquera également que Jérôme n'a pas cité Malachie 1, 4, où les Iduméens promettaient de reconstruire ce qui avait été détruit par Dieu et où ce dernier répondait qu'il les haïrait pour l'éternité. Soit il voulut éviter d'attribuer à Dieu une haine éternelle, soit il préféra ne pas rapporter ce témoignage biblique que les Juifs appliquaient à Rome.

Le texte sur Joë ${ }^{90}$ revient sur l'identification juive entre Rome et l'Idumée (et donc Édom) en affirmant qu'elle ne repose sur rien et que l'on pourrait aussi bien retenir d'autres peuples (Perses, Élamites, Francs et Alamans). Cette critique de ce que Jérôme présente comme une interprétation allégorique gratuite est néanmoins à nuancer, car on peut supposer qu'elle était rapprochée par les Juifs du jeu de lettres Duma/Roma, ce qui permettrait d'écarter les autres peuples. Par ailleurs, la mention conjointe dans la prophétie (Joël 3, 19) de l'Égypte et d'Édom permettait aux Juifs de faire le parallèle entre le premier et le dernier oppresseur d'Israël.

Pour Isaïe, Jérôme ${ }^{91}$ mentionne quatre prédécesseurs grecs (Origène ${ }^{92}$, Eusèbe de Césarée ${ }^{93}$, Didyme ${ }^{94}$ et Apollinaire de Laodicée) et un latin (Victorin de Pétau ; Jérôme connaissait sans doute celui d'Ambroise de Milan $^{95}$, mais n'appréciait guère ce dernier et ne le

90. In Ioelem 3 : « Et in hoc loco Iudaei grauissimo somno dormiunt, in ultimo tempore, quando non Christum, sed antichristum suscepturi sunt, uindictam sui, in Aegyptios qui uicini sunt, et in Romanos quos interpretantur Idumaeos, spe uanissima confingentes [...] aut cur pro Idumaeis intellegantur Romani, cum eadem licentia mentiendi e diuerso possimus asserere, sub Idumaeorum uocabulo uel Persas, uel Elamitas, uel Francos, Alamannos, gentes que alias significari ».

91. Sur les commentaires sur Isaïe avant Jérôme, voir P. Jay, L'exégèse de Saint Jérôme, p. 56-60.

92. In Isaiam, livre 5, préface : «subeam ne opus in quo uiri eruditissimi sudauerunt, Origenem loquor et Eusebium Pamphili, quorum alter liberis allegoriae spatiis euagatur, et interpretatis nominibus singulorum, ingenium suum facit ecclesiae sacramenta, alter historicam expositionem titulo repromittens, interdum obliuiscitur propositi et in origenis scita concedit? ». Jérôme avait traduit en latin le commentaire d'Origène dès 375-79; cf. Francesco Pieri, « Isaia 6 nell'esegesi di Girolamo », Annali di Scienze Religiose 5, 2000, p. 169-188.

93. In Isaiam, Prologue: «Eusebius quoque Pamphili iuxta historicam explanationem quindecim edidit uolumina »; V.18.2 : «Eusebius Caesariensis historicam interpretationem titulo repromittens ».

94. In Isaiam, Prologue : « et Didymus, cuius amicitiis nuper usi sumus, ab eo loco ubi scriptum est: consolamini, consolamini populum meum, sacerdotes; loquimini ad cor Hierusalem, usque ad finem uoluminis, decem et octo edidit tomos ».

95. Sur ce texte, voir Iginio Passerini, «La visione di Isaia in Ambrogio», Annali di Scienze Religiose 5, 2000, p. 153-168. 
cite pas ; mais ces commentaires latins, perdus, étaient avant tout allégoriques). Là aussi, on ne peut guère établir de parallèles textuels certains. Celui de Didyme commençait en Isaïe 40 (sans doute pour compléter celui d'Origène) et ne concerne pas les passages commentés ici. Apollinaire de Laodicée n'avait commenté, fort brièvement, que des points précis, et son œuvre est perdue. Selon Jérôme, Eusèbe adoptait une interprétation historique, mais en réalité celle-ci pouvait être double, car les prophéties pouvaient être comprises comme s'étant déjà réalisées ou comme se réalisant au temps présent de l'Église, solution que retenait souvent Eusèbe. Jérôme s'est parfois séparé d'Eusèbe sur ce point ${ }^{96}$, en lui reprochant alors de ne pas suivre la lecture historique sur le passé. Or, cette dernière était défendue à l'époque pour diverses raisons: sans doute par certains Juifs qui refusaient l'application des prophéties à l'Église ; par Porphyre de Tyr, qui dans son Contre les Chrétiens avait à la fin du $\mathrm{III}^{\mathrm{e}}$ siècle, défendu la lecture historique appliquée à Israël contre la lecture allégorique appliquée au Messie ou à l'Église ; par les exégètes antiochéens comme Théodore de Mopsueste, qui, acceptant la critique philologique et historique de Porphyre, pensaient ainsi pouvoir mettre en valeur les prophéties non réalisées et donc indiscutablement messianiques ou ecclésiologiques. Mais Jérôme ne connaissait pas ces derniers et il reprocha à Eusèbe de céder parfois à la tentation de l'interprétation allégorique ${ }^{97}$. Il existait d'autres commentaires sur Isaïe que Jérôme ne connaissait pas : celui de Théodore d'Héraclée (première moitié du $\mathrm{IV}^{\mathrm{e}}$ siècle, dont on n'a que des fragments dans les chaînes, $P G 18$ ) ; celui attribué (mais ceci est discuté) à Basile de Césarée ( $P G 30$ ), qui s'appuyait sur Origène ; et celui de Jean Chrysostome, conservé seulement en arménien pour les passages qui nous intéressent. En définitive, on ne peut réfléchir sur le texte de Jérôme qu'à partir d'Origène et d'Eusèbe.

96. In Isaiam V.22.2: «nos autem possumus et de Babylonia captiuitate dicere; quamquam Eusebius omnia ad Christi aduentum referat et putet Vespasiani Titique temporibus fuisse completa». Mais comme Jérôme n'était pas d'accord avec Eusèbe et qu'il ne pouvait pas rejeter l'interprétation de ce dernier, il la conserva en lui donnant un sens moral: "quod si in aduentu christi, iuxta Eusebium, tropologice intellegere uolueris, dices eos interfectos non gladio, sed infidelitate »; ibidem, : « quod que dicitur in extremo huius capituli in die illa, Eusebius priori iungit capiti, ne sequens prophetia huic tempori coaptetur; Hebraei autem et ceteri explanatores sequenti, quod nunc proposituri sumus ».

97. P. Jay, L'exégèse de Saint Jérôme, p. 221-222. 
Le commentaire d'Origène sur Isaïe est perdu, mais il est possible qu'il soit allé jusqu' au chapitre 35 ou $39^{98}$. Il a pu en théorie influencer Jérôme dans sa lecture d'Isaïe 21, 11, ou d'Isaïe 34, 6-7 et 34, 10-17. Néanmoins, on ne trouve rien pour notre propos dans les homélies d'Origène sur Isaïe, conservées en partie dans la traduction latine de Jérôme (GCS 33). Et il n'y a rien de semblable dans les autres commentaires sur Isaïe qui se sont inspirés d'Origène. De plus, la remarque sur les lettres hébraïques (Isaïe 21, $11^{99}$ ) provient plutôt d'un contemporain juif de Jérôme. Enfin, il faut distinguer l'aspect philologique de l'aspect interprétatif. Généralement, Origène, une fois la lettre (grecque) des Écritures fixée, proposait un commentaire allégorique et ne s'intéressait guère au sens historique, à la différence de ce que firent ensuite Eusèbe de Césarée ou Théodore de Mopsueste. Aussi, on peut penser que le texte de Jérôme en 21, 11 est une interprétation originale.

Dans son Commentaire sur Isaïe $e^{100}$, Eusèbe de Césarée parle bien en Isaïe 34, 5-6 de Bosor (Bosra), qu'il met en rapport avec l'Idumée et Édom ${ }^{101}$. Mais il ne fait qu'une lecture étymologique de ce passage, donnant une traduction grecque du mot hébreu (Édom signifie «terrestre » $)^{102}$. Eusèbe avait signalé avoir eu recours à un exégète juif en Isaïe 29, 1 (pour poser une équivalence entre Ariel et Jérusalem), mais il ne dit rien en ce sens à propos d'Isaïe 34, 5-6. Le commentaire de Jérôme sur Isaïe 34, 6-7 $7^{103}$ ne suit pas celui d'Eusèbe (en particulier, il ajoute Dumah et ne traduit pas Édom) et ajoute que

98. Roger Gryson et Dominique Szmatula, «Les commentaires patristiques sur Isaïe d'Origène à Jérôme », Revue des Études Augustiniennes 36, 1990, p. 3-41, en particulier p. 13-15.

99. In Isaiam 21.11: « Hoc iuxta historiam dictum sit; ceterum propter similitudinem litterae, ex eo quod res et daleth non multum inter se discrepent, quidam Hebraeorum pro Duma Romam legunt, uolentes prophetiam contra regnum Romanum dirigi, friuola persuasione, qua semper in Idumaeae nomine Romanos existimant demonstrari ».

100. Sébastien Morlet, La Démonstration évangélique d'Eusèbe de Césarée. Étude sur l'apologétique chrétienne à l'époque de Constantin, Paris, Institut d'Études augustiniennes, 2009, p.600-611, établit des parallèles entre les commentaires d'Origène, d'Eusèbe et du Pseudo-Basile.

101. GCS 57, p. 223.

102. Comme il le fait ailleurs : Michael J. Hollerich, Eusebius of Caesarea's Commentary on Isaiah: Christian exegesis in the age of Constantine, Oxford, Clarendon Press, 1999, p. 73.

103. In Isaiam 34.7 : «Bosra, id est munitam atque firmatam, et Edom, siue Duma, et Idumaeam, Iudaeorum magistri Romam intellegi uolunt, et omnia de ipsa dici quae sequenti capitulo continentur $»$. 
les maîtres des Juifs comprennent Édom comme désignant Rome, ce qui n'est pas chez Eusèbe. Mais Jérôme ne mentionne pas le jeu de mot rabbinique en Isaïe 34, 7 sur buffles - reémim - et Romains - romiyim - dans la phrase « les buffles tomberont».

Ensuite, Eusèbe de Césarée interprète Isaïe 34, 9-10 en lien non avec Édom comme dans le texte biblique, mais avec Jérusalem ${ }^{104}$. Là où le texte biblique annonçait le châtiment d'Édom, Eusèbe interprète qu'il s'agit de celui de Jérusalem, ce que permettait la version LXX d'Isaïe 34, 8 qui diverge du TM en évoquant « un jour de jugement du Seigneur et une année de paiement en retour, de jugement de Sion ». Pour Eusèbe, le jugement de Sion est compris comme un jugement contre Sion, ce qui implique sa désolation, qui trouve son point culminant dans la ruine que lui infligent les Romains. Eusèbe écrit que l'Écriture indique clairement (dans les vers 9-10) que la désolation s'emparera et du lieu et du peuple, qu'il n'y aura plus personne pour traverser la ville ou s'y promener. Et il ajoute que l'Écriture prophétise par ces paroles qu'aucun Juif ne traversera plus le lieu, et que cette prophétie «a été accomplie par les lois et les ordonnances romaines (à propos des) Juifs empêchés de résider dans le lieu ». Ainsi, non seulement Eusèbe n'assimile pas Édom aux Romains, mais il applique la prophétie relative à Édom à Jérusalem, et voit dans les Romains un instrument du châtiment des Juifs ${ }^{105}$. En conclusion, en Isaïe 34, 5-6, Eusèbe parle d'Édom sans mentionner Rome, et en Isaïe 34, 10, il parle de Rome sans mentionner Édom.

En revanche, Jérôme cite l'équivalence juive entre Édom et Rome en Isaïe 34, 7, à propos de Bosra, et signale que les maîtres des Juifs comprennent le passage suivant $(34,8-17)$ de la même façon. Si lui-même interprète, comme Eusèbe, la désolation du lieu d'Isaïe 34, 10-17 comme étant celle de Jérusalem après sa destruction par les Romains, il rapporte néanmoins par deux fois, au début ${ }^{106}$ et à la fin ${ }^{107}$ de son commentaire, l'interprétation juive selon

104. GCS 57, p. 224.

105. Je remercie Katell Berthelot pour son aide concernant la compréhension de ce passage.

106. In Isaiam 34.8 : « Hebraei, ut supra diximus, haec de Romano imperio prophetata contendunt, et in ultionem Sion, uastitatem quondam regni potentissimi praedicari, quod iuxta litteram plerique nostrorum etiam in apocalypsi Ioannis scriptum putant ».

107. In Isaiam 34.10-17: «haec iuxta Hebraicum et explanationem historicam dicta sint $[\ldots]$ ceterum qui tropologiam sequuntur $[\ldots]$ sic allegorice interpretabimur $[\ldots]$ quae nos super Hierusalem diximus prophetari, et Iudaei de 
laquelle le texte s'appliquera à Rome, et la renvoie explicitement (ut supra diximus) à 34, 7, où était posée l'équivalence avec Édom. Mais Jérôme refuse cette interprétation car le texte s'applique à une ville et non au monde et ne peut donc concerner l'empire romain ${ }^{108}$.

Jérôme connaissait divers types d'exégèse des textes bibliques. La lecture historique pouvait être double selon qu'elle portait sur le passé contemporain des prophètes (lecture parfois qualifiée d'hébraïque ${ }^{109}$ ) ou sur le présent romain et ecclésiastique. L'exégèse allégorique pouvait voir dans les mentions d'Israël une allégorie de l'Église. L'exégèse prophétique concernait le Christ ${ }^{110}$. La compréhension tropologique amenait à une lecture psychologique ou morale de la prophétie. Enfin, l'interprétation que Jérôme qualifiait de « juive » était en réalité eschatologique, comprenant de manière historique figurative les malédictions contre Édom ou Ésaü comme devant se réaliser contre Rome lors des temps messianiques au profit d'Israël. Jérôme chercha à disqualifier cette approche, en la qualifiant d'allégorique, au nom d'une lecture historique. Mais le fait qu'il l'ait citée prouve ou bien qu'il discuta avec des Juifs de son temps en Palestine, ou que ces idées, peut-être déjà présentes chez ses prédécesseurs grecs, lui semblaient assez importantes pour être de nouveau réfutées. Mais nous n'avons trouvé aucun parallèle grec antérieur. De plus, il faut noter que Jérôme fut le seul à faire cela dans la tradition latine. Or, celle-ci utilisa un certain nombre de modèles grecs, en particulier Origène. On peut donc conclure plutôt en faveur d'informations que Jérôme a obtenues en discutant avec des rabbins de Palestine. Il semble avoir été le seul de son temps ; en particulier, les exégètes antiochiens comme Théodore de Mopsueste ne mentionnent pas d'interprétations juives exégétiques

Romano dicta imperio suspicantur, nonnulli ad orbem referunt, ne a prioribus discrepare uideantur ».

108. Sur les relations générales de Jérôme vis-à-vis des interprétations des Juifs, voir P. Jay, L'exégèse de Saint Jérôme, p. 196-200.

109. C'était à la même époque l'approche de Théodore de Mopsueste et ensuite de Julien d'Éclane (sur Osée, Joël et Amos, CCSL 88). Mais on ne peut établir de parallèle entre Jérôme et eux, cf. P. Jay, L'exégèse de Saint Jérôme, p. 402-404. D'ailleurs, les exégèses d'Iso'Dad de Merv ( $\mathrm{IX}^{\mathrm{e}}$ siècle) sur Isaïe et les petits prophètes, qui s'inspirent principalement de Théodore de Mopsueste, principal interprête de l'Écriture aux yeux de l'église syro-orientale ( «nestorienne»), ne reprennent pas l'équivalence entre Rome et Ésaï ou Édom; voir le Commentaire d'Iso'Dad de Merv sur l'Ancien Testament. IV, Isaïe et les Douze, édité et traduit par Ceslas Van den Eynde, CSCO 303-304, Louvain, Peeters, 1969.

110. P. Jay, L'exégèse de Saint Jérôme, p. 376-379. 
dans leurs œuvres analogues. Mais si cette hypothèse est exacte, on peut aussi en déduire soit que les chrétiens ne discutaient guère avec les Juifs dans les autres régions de l'empire romain, soit que l'audience de la tradition rabbinique n'était pas très importante dans le monde romain vers 400 en dehors de la Palestine, ce qui est vraisemblable.

\section{Conclusion}

Dans la plupart des cas, les équivalences bibliques de Rome furent incluses dans un contexte mental messianique et eschatologique, où la fin de Rome, conçue comme le dernier empire terrestre, signifiait nécessairement le temps de la rédemption et de la gloire d'Israël pour les Juifs ou de la cité de Dieu pour les chrétiens.

Si les Kittim ont rapidement disparu et si l'interprétation de Tyr comme figure de Rome est restée marginale, on note que le judaïsme rabbinique a privilégié l'équivalence entre Rome et Ésaü, et les chrétiens celle entre Rome et Babylone. Seul Aphraate connaissait assez bien le raisonnement rabbinique pour le reprendre et le subvertir de l'intérieur par une transformation de la signification messianique. Les chrétiens de langue grecque et de langue latine, mais aussi les autres chrétiens de langue syriaque comme Éphrem, agirent autrement. Vis-à-vis d'Édom, ils adoptèrent une lecture historique portant sur un passé lointain, ou une lecture allégorique morale ou spirituelle. Et en interprétant Jacob - Israël comme désignant les chrétiens et Ésaü - Édom comme symbole des Juifs, ils pratiquèrent une telle inversion des valeurs qu'elle rendait tout dialogue impossible, même si Augustin distingua la dimension charnelle de l'aspect spirituel des filiations de Jacob et d'Ésaü. Cependant, en s'appropriant Jacob, et ne pouvant plus décrire les Romains chrétiens par rapport à Ésaü, les chrétiens durent privilégier le parallèle entre Rome et Babylone, seule figure biblique qui restait disponible. Toutefois, à côté de cette équivalence allégorique, on note le lien historique et typologique entre Babylone et Rome comme nouvelle Babylone en Occident, qui fut principalement développé par Augustin et Orose.

Le cas des travaux exégétiques de Jérôme pose le problème de ses relations avec la littérature rabbinique et plus encore de la datation des traditions de cette dernière. À propos de l'équivalence entre Ésaü, Édom et Rome, on peut dater de manière certaine les 
écrits d'Aphraate en 337 (pour Ésaü) et de Jérôme en 392-410 (pour Édom). La manière dont Aphraate parle des fils d'Ésaü montre qu'il fait référence à une évidence culturelle. On peut donc supposer que l'équivalence existait chez les Juifs mésopotamiens avant 324, et qu'Ésaü ne désigna pas seulement les Romains chrétiens (ou plutôt les Romains dirigés par un empereur chrétien ${ }^{111}$ ), puisqu'Aphraate fait allusion à des batailles perdues par les Romains au III $^{\mathrm{e}}$ siècle. Quant à l'équivalence entre Édom et Rome que rapporte Jérôme - et il est, semble-t-il, le seul parmi tous les commentateurs chrétiens grecs et latins conservés à le faire-, elle vient d'informateurs palestiniens contemporains et elle est à rapprocher de Genèse Rabbah, texte compilé vers 400. Mais c'est là le travail des spécialistes du judaïsme ${ }^{112}$.

Enfin, il faut noter qu'au Moyen Âge (et jusqu'à aujourd'hui sur certains sites internet), des Juifs virent dans les chrétiens les descendants de Rome - Ésaü. De plus, que ce soit via les Juifs ou via les chrétiens syriaques, le thème des Romains comme descendants d'Ésaü (ou parfois de Jacob) fut connu des musulmans : on le retrouve par exemple chez Tabarî. De même, il est présent dans la tradition syriaque tardive, comme chez Michel le Syrien qui proposa une identification entre les fils d'Ésaü et les « Francs » (les croisés européens) dans sa chronique.

herve.inglebert@u-paris10.fr

111. En revanche, il s'agit bien de ceux-ci dans $y$. Nedar. III, 10, commenté par Marcel Simon, Verus Israel. Étude sur les relations entre chrétiens et juifs dans l'empire romain (135-425), Paris, Éditions De Boccard, 1948, p. 223.

112. Voir par exemple Louis Ginzberg, « Die Haggadah bei den Kirchenvätern 6. Der Kommentar des Hieronymus zu Jesaja », Jewish Studies: In memory of George A. Kohut, 1874-1933, dir. Salo W. Baron et Alexander Marx, New York, 1935 ; voir aussi Michael Lattke, "Haggadah», Reallexicon für Antike und Christentum 13, col. 347-348 sur Origène et Jérôme. 